\title{
ANÁLISE CINEMÁTICA MESOSCÓPICA DOS CAVALGAMENTOS DO CINTURÃO ESPINHAÇO NA REGIÃO DE DIAMANTINA, MG
}

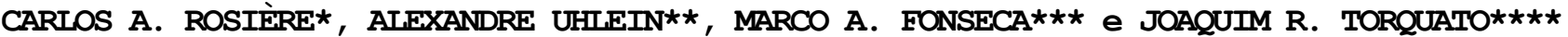

\begin{abstract}
MESOSCOPIC KINEMATIC ANALYSIS OF THE THRUSTS OF THE ESPINHAÇO BELT IN THE REGION OF DIAMANTINA, MG. The structural analysis of an outcrop of quartzite belonging to the Diamantina Group, Espinhaço Supergroup, near the town of Diamantina, Minas Gerais allows the interpretation of at least. part of the structural evolution and the characterization of the tectonic style of the western Espinhaço Cordillera. Early intense interlayer slip was followed by the nucleation of WSW-vergent flexural slip folds and developrnent of thrusts. The structures are characteristic of thin-skinned tectonism, under ductile to brittle-ductile conditions and greenschist fácies metamorphism. The temperature effect outlasted that of the deformation.
\end{abstract}

Keywords: Espinhaço Supergroup, thin-skinned tectonics, structural analysis.

RESUMO A análise geométrica e cinemática de um excepcional afloramento de quartzitos e filhos do Grupo Diamantina, nas proximidades da cidade homónima, permitiu a interpretação da história da evolução das estruturas ali formadas, que representam, em escala mesoscópica, a estruturação macroscópica da porção ocidental da Serra do Espinhaço. A evolução da tectônica compressional iniciou-se com intenso deslizamento interestratal, seguido de nucleação de dobras de deslizamento flexural e desenvolvimento de falhas de cavalgamento, aproximadamente dentro de um mesmo plano cinemático, com transporte de ENE para WSW. A deformação ocorreu dentro de tectônica epitelial, em condições rúpteis a dúctil-rúpteis, tendo as rochas sofrido fraco metamorfismo (fácies xisto verde) e a temperatura perdurado até o final do tectonismo.

Palavras-chave: Supergrupo Espinhaço, tectônica epitelial, análise estrutural.

INTRODUCÃ̃O $\mathrm{Na}$ região de Diamantina (MG), as formações basais do Supergrupo Espinhaço apresentam-se dobradas e cavalgadas em condições metamórficas da fácies xisto verde, apresentando, de modo geral, baixo grau de deformação entre zonas de cisalhamento discretas, resultando em espessura anómala, no pacote de metassedimentos, e desenvolvimento de estruturas típicas de tectônica epitelial. Na BR-367, próximo da cidade, em frente ao marco quilométrico 584, identificou-se um excepcional afloramento (Fig. 1), constituido por quartzitos com intercalações de filitos e metabrechas pertencentes ao Grupo Diamantina. O objetivo deste trabalho é descrever em detalhe o afloramento, caracterizar as estruturas micro e mesoscópicas presentes, proceder à análise cinemática e integrar os dados descritos à evolução estrutural da Serra do Espinhaço Meridional.

\section{A ESTRUTURA DA SERRA DO ESPINHACO} MERIDIONAL No Segmento Espinhaço podem-se reconhecer duas unidades litoestratigráficas, conforme Dossin et al (1984): Grupo Diamantina (basal) e Grupo Conselheiro Mata (superior). O Grupo Diamantina predomina a Leste e é constituido pelas Formações São João da Chapada, Sopa-Brumadinho e Galho do Miguel (Pflug 1968, Schöll \& Fogaça 1979). A oeste, ocorre o Grupo Conselheiro Mata, com as Formações Santa Rita, Córrego dos Borges, Córrego Bandeira, Córrego Pereira e Rio Pardo Grande (Pflug 1968, Schöll \& Fogaça 1979).

A estruturação da Serra do Espinhaço está condicionada a tectônica de cavalgamentos, reconhecida desde o início da década de 80 (Hergesell 1984, 1985, Almeida Abreu et al
1986). Uhlein et al. (1986) e Uhlein \& Trompette (1993), baseados no estilo de deformação e comportamento das rochas aflorantes, caracterizam dois domínios principais de deformação: a Leste da Serra do Espinhaço, desenvolve-se tectônica de cavalgamentos, na maioria das vezes frontais, de direção meridiana, vergentes para oeste. Neste domínio, é maior a magnitude de deformação, desenvolvendo-se foliação milonitica juntamente com conspícua lineação de estiramento - que marca a direção de transporte tectônico.

O domínio ocidental distingue-se do oriental pela baixa magnitude de deformação imposta às rochas do Supergrupo Espinhaço. Nele predominam dobras amplas assimétricas, com xistosidade plano axial submeridiana, eventualmente cortadas por falhas inversas N-S.

Segundo Uhlein (1991), a região estudada neste trabalho constitui o domínio transicional da faixa de Dobramentos Araçuaí, de idade brasiliana. Nesse contexto, a região exibiria três fasjes de deformação, dentro de um único evento tectônico. Â fase de deformação mais importante relacionase o principal conjunto de cavalgamentos e falhas reversas, dobras e zonas de cisalhamento dúctil-rúpteis em todas as escalas. Lineações de estiramento, de interseção, xistosidades e foliação milonítica associam-se às principais estruturas meso e macroscópicas.

DESCRIÇÃO GERAL DO AFLORAMENTO afloramento em estudo, por suas características petrográficas e estruturais, pode ser dividido em cinco setores (Fig. 2). - Setor I - Está situado na extremidade NE do corte, limitado a S W pela falha reversa F,. A litologia presente é um

\footnotetext{
* Departamento de Geologia, Universidade Federal de Minas Gerais, Avenida António Carlos 6627, CEP 31270-901, Belo Horizonte, MG, Brasil, Fax (031) 4413787

** Departamento de Geologia, Universidade Federal de Minas Gerais, Avenida António Carlos 6627, CEP 31270-901, Belo Horizonte, MG, Brasil, $\operatorname{Fax}(031) 4485410$

*** Departamento de Geologia, Escola de Minas, Universidade Federal de Ouro Preto, Campus Morro do Cruzeiro, CEP 35400-000, Ouro Preto, MG, Brasil 


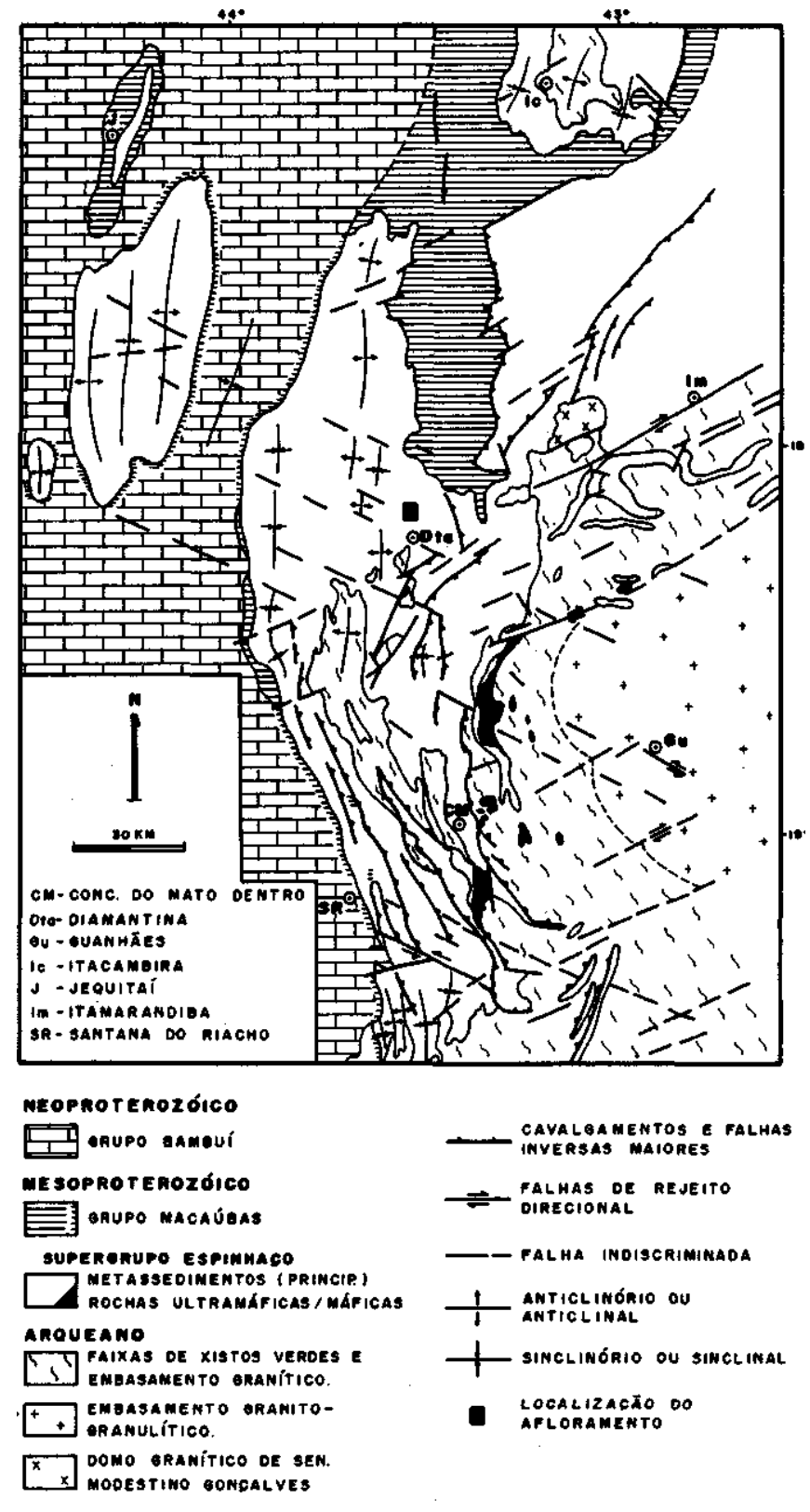

Figura 1 - Mapa geológico-estrutural da Serra do Espinhaço com localização do afloramento estudado (retirado de Almeida Abreu 1993)

Figure 1 - Structural geological map of the Espinhaço Cordillera with location of the studied outcrop (from Almeida Abreu 1993)

quartzito micáceo, fracamente foliado, de granulometria média, mostrando tanto estratificação cruzada acanalada de pequeno porte, quanto plano-paralela, mergulhando, em média, $30^{\circ}$ para NE. Neste setor, predominam típicas estruturas de cavalgamento com zonas de cisalhamento discretas, paralelas ao acamamento, de onde se diverticulam rampas frontais que truncam as camadas (Fotos 1 e 2). - Setor II - É limitado pelas falhas reversas F 1 e F2, sendo F2 a SW, onde afloram quartzitos de características semelhantes aos encontrados no Setor I, em posição suborizontal. Alguns níveis filíticos de espessura centimétrica e lâminas ferruginosas estilolíticas estão intercalados. Neste bloco, a foliação nos quartzitos apresenta-se mais bem desenvolvida, havendo obliteração das estruturas primárias nas proximidades da falha $\mathrm{F} 2$, com o desenvolvimento de milonitos (Fotos 3 e 4).
- Setor III - É caracterizado pelo bloco limitado pelas falhas F2 e F3, onde aparecem quartzitos de granulometria média a grossa, com estratificação cruzada e intercalações de níveis micáceos e ferruginosos, como no Setor II (Foto 3). Os estratos apresentam-se suborizontais, suavemente ondulados até a extremidade SW, onde encontram-se dobrados, havendo inversão na sequência, em um anticlinal assimétrico, de flanco invertido, truncado pela falha F3.

- Setor IV - Neste bloco, limitado pela falhas F3 e F4, os quartzitos mostram-se fortemente decompostos, não sendo possível a caracterização de estruturas menores . Na extremidade SW, o quartzito passa bruscamente, mas sem descontinuidade a uma metabrecha com fragmentos e seixos de quartzito branco, envolvidos em matriz arenosa, localmente ferruginosa, cortada por grande número de veios de quartzo, na maioria, subverticais. Os fragmentos estão em parte contornados por foliação anastomosante, quando então apresentam-se deformados, com a forma lenticular, achatados no plano de foliação, e incipiente orientação linear. $\mathrm{O}$ contato dessa rocha com quartzitos subjacentes é marcado pela falha $\mathrm{F} 4$, que limita a SE os setores IV e V.

- Setor V - Na extremidade SW do afloramento, sotopostos à falha $\mathrm{F} 4$, ocorrem quartzitos intercalados com filitos ferruginosos de cor cinza, passando a ritmitos, que exibem dobras assimétricas de dimensões decimétricas. Os filitos apresentam nítido bandamento paralelo ao acamamento, caracterizado por lâminas de hematita e são cortados por forte clivagem de crenulação em posição plano-axial. Corta o afloramento um grande número de veios de quartzo, de espessura centimétrica, orientados paralelamente ao acamamento, dentro das zonas de cisalhamento.

CARACTERIZAÇÃO DAS ESTRUTURAS Falhas de cavalgamento As rochas da área em análise foram submetidas a tectônica compressiva, na qual falhas de cavalgamento são as estruturas dominantes. Quatro falhas principais cortam o afloramento ( $\mathrm{Fl}$ a F4), definindo os blocos acima descritos (setores I a V, Fig. 2). Elas apresentam-se como rampas frontais, com F3 mostrando características de rampa oblíqua. F 1 e F3 truncam os flancos curtos de dobras assimétricas mesoscópicas, enquanto F2 corta o acamamento suborizontalizado. F4, por sua vez, tem posição indefinida quanto a estratificação, pois corta o corpo de metabrecha em que o acamamento não é visível. Aparentemente, F4 o corta em sua base.

Junto às zonas de falha, desenvolvem-se milonitos, principalmente em F2 (Fotos 3 e 4), onde a proporção de filossilicatos aumenta significativamente, com o desenvolvimento de bandamento descontínuo, devido à alternância de faixas quartzosas e micáceas, envolvendo blocos de quartzito de morfologia amendoada. Em F4 ocorre também cataclase, com as fraturas sendo preenchidas por veios de quartzo.

Internamente a cada setor, principalmente em I, desenvolveram-se falhas e zonas de cisalhamento de menor porte, em condições rúpteis a dúctil-rúpteis, com geometria de rampas e patamares, sendo estes últimos controlados pelo acamamento (Fotos 1 e 2). Mesoscopicamente, forma-se estruturação típica de duplex, com bloços cavalgados, superpostos em empilhamento estrutural. É difícil determinar o deslocamento sofrido por cada fatia entre zonas discretas, tanto pelo seu caráter rúptil, como devido a homogeneidade dos quartzitos.

$\mathrm{O}$ diagrama de pólos das falhas e zonas de cisalhamento de alto ângulo mostra máximo estatístico de 147/60NE (Fig. $3 \mathrm{c}$ ), indicando homogeneidade de atitude para essas estruturas em todo o afloramento. As zonas de cisalhamento de mais baixo ângulo, correspondentes a patamares paralelos ao acamamento, têm atitude também constante, com um único máximo em projeção estereográfica $174 / 40 \mathrm{NE}$ 


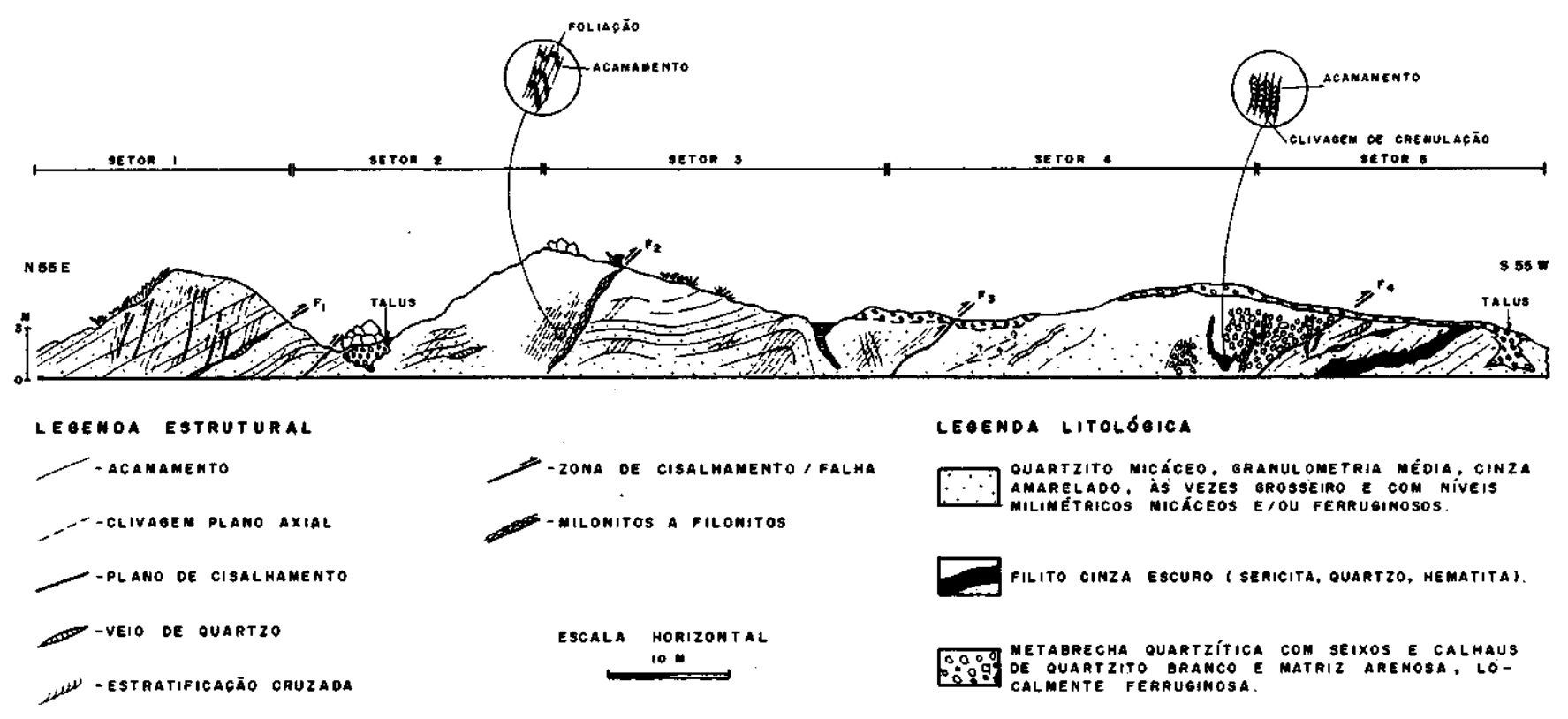

Figura 2 - Afloramento no Km 584, Rodovia BR-367, Diamantina, MG. Domínios e elementos estruturais

Figure 2. - Outcrop at km 584, highway BR-367, Diamantina. Structural domains and elements

(Fig. 3d), valor próximo ao principal máximo do diagrama em guirlanda obtido nas medidas de acamamento (Fig. 3a). As falhas estão quase sempre acompanhadas por faixas milonitizadas, principalmente nos setores I e II, atestando desenvolvimento sob condições parcialmente dúcteis, formando-se foliação milonítica, de morfologia anastomosada, com estruturas do tipo foliation fish, mas que não afeta o pacote de quartzitos de forma penetrativa.

Dobras Nos quartzitos, o acamamento mostra-se dobrado em estruturas de dimensões métricas, de ângulo apical aproximadamente $60^{\circ}$, charneiras arredondadas com perfil típico de dobras paralelas, mantendo a espessura dos estratos constante com isógonas convergentes (tipo Ib, Ramsay 1967). São invariavelmente assimétricas, com vergência para WNW, flanco curto rompido por falhas inversas e eixo suborizontal, de orientação segundo o azimute $340^{\circ}$ (Fig. 3a). As dobras parasíticas mostram vergência variável, sempre para o núcleo da estrutura maior. Podem ser geneticamente classificadas como de deslizamento flexural, o que é atestado pelas estrias de deslizamento nos planos de estratificação. Mostram foliação plano-axial de morfologia anastomosada. O estereograma das medidas de acamamento mostra típica distribuição em guirlanda assimétrica, com máximo 162/30NE com eixo suborizontal, grosseiramente, segundo a direção N-S (Fig. 3a).

Nos filitos, o dobramento é mais intenso, com a maior nucleação dessas estruturas, de dimensões decimétricas, que se apresentam mais apertadas, provavelmente por flambagem seguida de achatamento. A vergência, assim como a orientação de seu eixo, é concordante com os dados encontrados no quartzito. O bandamento original, caracterizado pela alternância de níveis hematíticos e micáceos, permitiu o desenvolvimento de clivagem de crenulação, em posição plano-axial, podendo ocorrer transposição do bandamento, com a quase total obliteração dessa estrutura planar.

Foliações Xistosidade Nos quartzitos, desenvolve-se xistosidade de morfologia anastomosada, caracterizada pela orientação de palhetas de sericita envolvendo porfiroclastos pouco deformados de quartzo, apresentando extinção ondulante e, raramente, bandas de deformação (Foto 5), subgrãos irregulares com novos grãos recrista- lizados nas bordas (microestrutura do tipo core and mantle), chegando a rocha a adquirir estrutura protomilonítica. $\mathrm{Na}$ metabrecha do Setor IV, a morfologia anastomosada é particularmente notável pelas dimensões decimétricas dos fragmentos que constituem a rocha.

Nos domínios que apresentam baixa magnitude de deformação, a xistosidade está em posição aproximadamente plano-axial às dobras ali desenvolvidas; nas zonas de cisaIhamento e falhas reversas em posição de rampa frontal, ela se mostra paralela aos planos de transporte dessas estruturas. Embora a intensidade da foliação varie com a deformação, a sua atitude permanece praticamente constante, com o estereograma apresentando um único máximo (147/60NE, ver Fig. 3b), idêntico ao determinado por intermédio do diagrama da figura $3 c$, a partir de medidas das falhas e zonas de alto ângulo.

$\mathrm{O}$ desenvolvimento descontínuo de zonas de cisalhamento paralelas ao acamamento, particularmente nos flancos longos das dobras macroscópicas, provoca a rotação da xistosidade e lhe confere aspecto sigmoidal. Em projeção estereográfica, esse fato reflete-se no aspecto alongado da distribuição dos pontos.

Nas zonas de cisalhamento, os quartzitos apresentam-se milonitizados, com total recristalização da rocha, o que provoca a substituição dos porfiroclastos por um agregado de cristais poligonais, com pontos triplos, e livres de extinção ondulante e outras microestruturas de origem deformacional (foam structure), entre palhetas de sericita fortemente orientadas, definindo a xistosidade (Foto 6). O estágio mais avançado de milonitização observa-se na falha $\mathrm{F}_{2}$, onde a proporção de filossilicatos aumenta por diferenciação, resultando em bandamento pela alternância de níveis micáceos e quartzosos, nos quais esses minerais mostram-se totalmente recristalizados. Os filitos, por sua vez, também apresentam foliação bastante penetrativa, paralela ao acamamento com a orientação da sericita e palhetas de hematita.

Clivagem de crenulação Nos filitos, desenvolve-se clivagem de crenulação cortando o bandamento existente, definido pela intercalação de níveis alternados de sericita e hematita. Nas dobras mais apertadas, ocorre transposição como produto final do desenvolvimento da clivagem, resultando em novo bandamento hematita/filossilicatos por dife- 

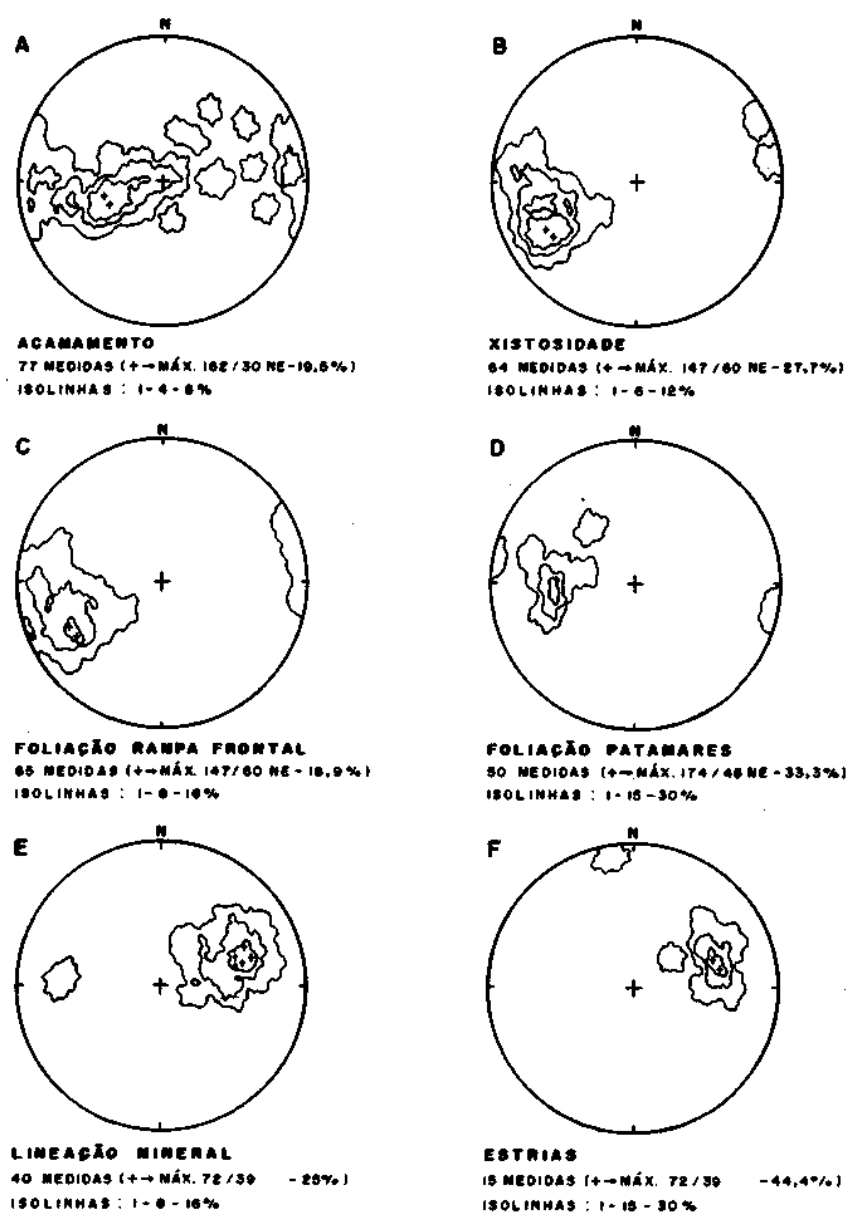

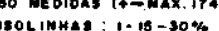

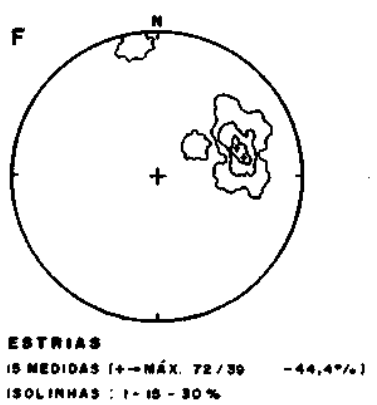

Figura 3 - Estereogramas dos principais elementos estruturais do afloramento estudado

Figure 3 - Stereograms of the main structural elements of the outcrop

renciacão (Foto 7). Nas estreitas zonas de cisalhamento paralelas ao acamamento, o bandamento mostra-se totalmente destruído, substituído por foliação contínua de trajetória sinuosa, formando-se então um filonito.

Lineações Quatro tipos de lineações podem ser caracterizadas no afloramento: lineação de intersecão, lineação mineral, lineação de estiramento e estrias de deslizamento.

As primeiras são produto da interseção entre o acamamento e a xistosidade, nas zonas de baixa deformação. Elas possuem orientação estatisticamente paralelas ao eixo das dobras encontradas.

A lineação mineral é caracterizada pela orientação das palhetas de sericita, em corte no plano perpendicular à foliação e paralela à lineação visível no afloramento (plano $\mathrm{XZ}$ ); a de estiramento é resultado da deformação dos grãos porfiroclásticos de quartzo e fragmentos de rocha na metabrecha, que provocou a modificação de sua forma original. Estas lineaçôes mostram idêntica orientação com as estrias de deslizamento. A análise estatística dos dados de campo mostram máximo de 72/39 para essas estruturas lineares (Fig. 3e - 3f), indicando homogeneidade cinemática para todas as famílias de estruturas.

ASPECTO CINEMÁTICO DAS ESTRUTURAS Em termos cinemáticos, a característica marcante das estruturas é o seu padrão assimétrico, tanto em escala meso quanto microscópica.
Mesoscopicamente, ressalta-se a assimetria das dobras e sua clivagem plano-axial, que possuem vergência constante para WNW. Nas zonas de cisalhamento e falhas inversas presentes, as estrias de deslizamento, juntamente com a foliação de morfologia sigmoidal e lineação mineral desenvolvidas nas faixas milonitizadas, são indicativos das condições de deformação não-coaxial, com transporte de ESE para WNW.

Internamente às zonas de cisalhamento, o aspecto sigmoidal da foliação milonítica (foliation fishes) pode ser observado ao microscópio, resultando em estruturas S/C (Foto 8) que, juntamente com porfiroclastos mostrando sombras de pressão assimétricas e microestruturas do tipo pull-apart, atestam a cinemática deduzida das observações de caráter mesoscópico.

\section{CARACTERÍSTICAS DA EVOLUÇÃO ESTRUTURAL}

As diversas meso e microestruturas descritas permitem uma interpretacão sobre a evolução estrutural do afloramento e suas implicações na tectônica do Supergrupo Espinhaço. A estruturação do afloramento é condicionada por tectônica de cavalgamentos, apresentando as seguintes características evolutivas, representadas esquematicamente na figura 4:
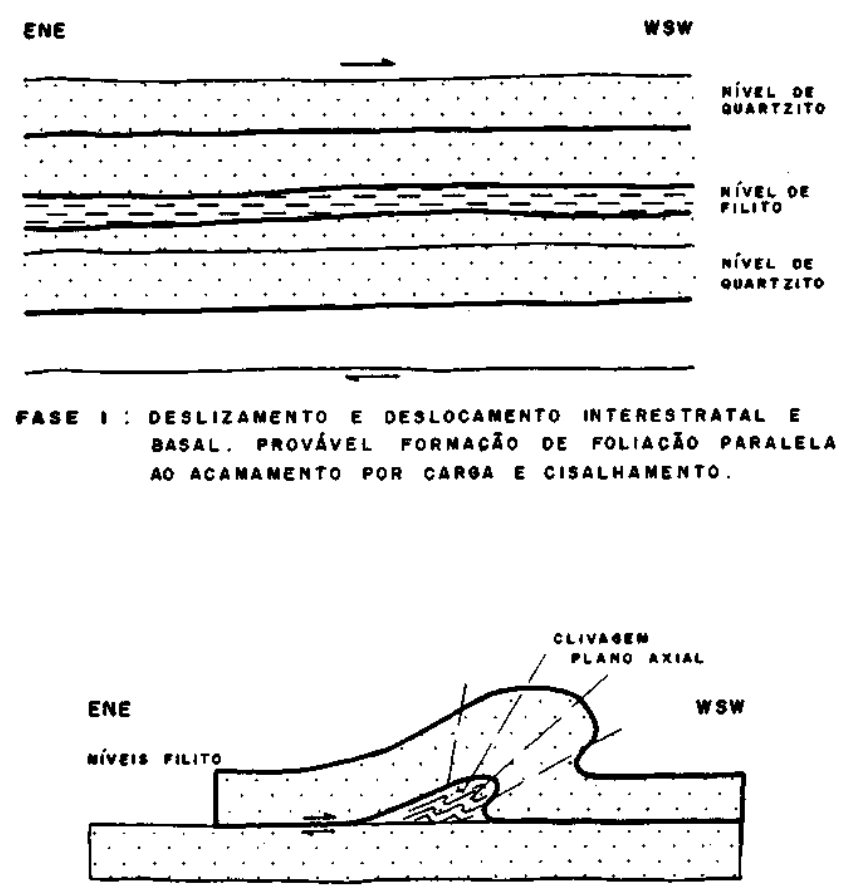

FASE 2 : NUCLEACÃo DE DOBRAS NA CAMAdAS DESCOLAdAS EM DIVERSAS ESCALAS COM DESENVOLVIMENTO DE CLIVA GEM PLANO AXIAL.

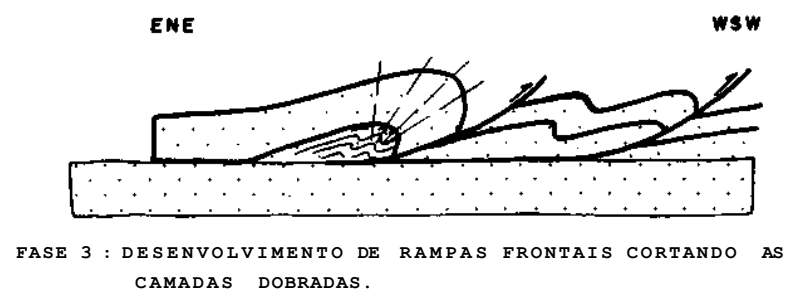

Figura 4 - Representação esquemática da evolução cinemática das estruturas

Figure 4 - Schematic representation of the kinematic evolution 


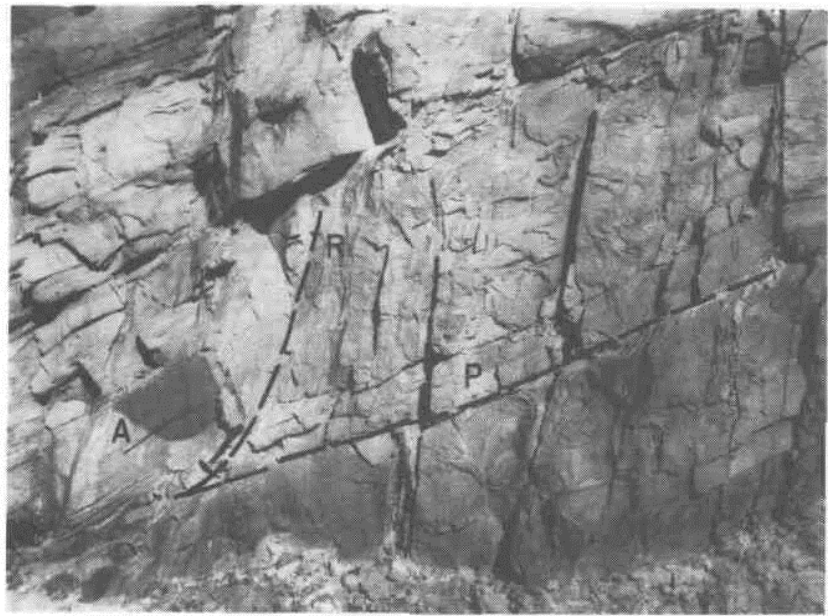

1

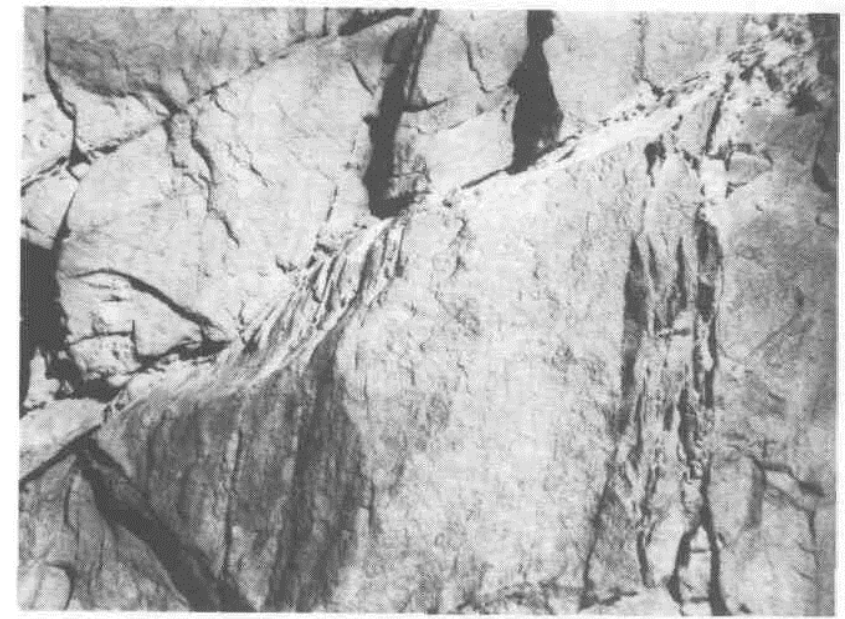

2

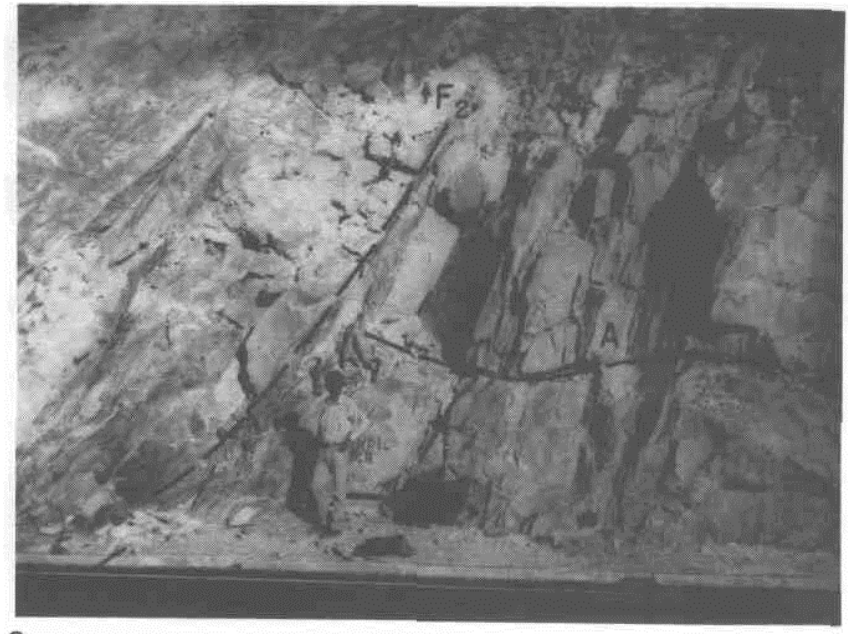

3

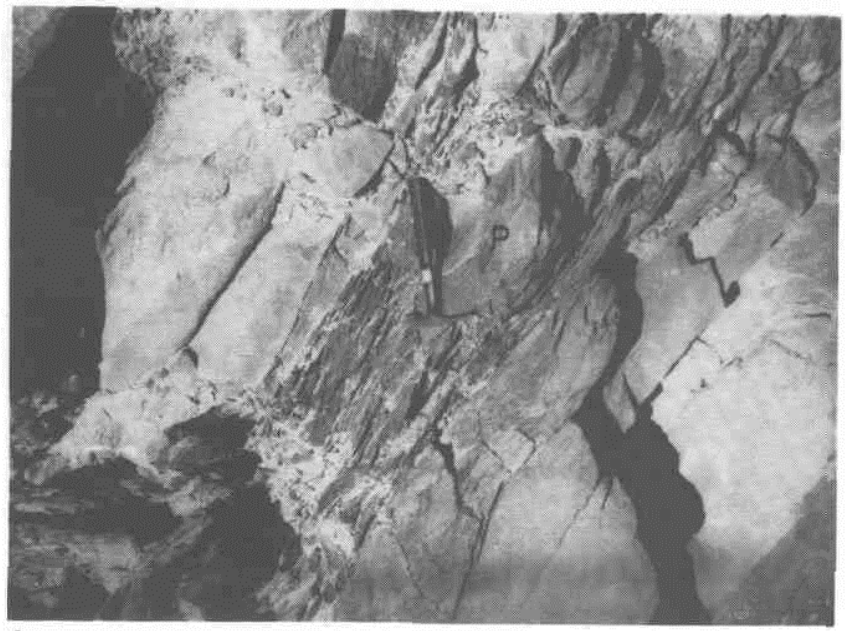

4

Prancha 1 - Foto 1. Setor I do afloramento, apresentando macroscopicamente acamamento (A), zonas de cisalhamento paralelas ao acamamento (P) - correspondentes a patamares e zonas de cisalhamento de alto ângulo ramificando dos planos suborizontais (R) - correspondentes a rampas frontais de cavalgamentos. Foto 2. Detalhe da foto 1, com zonas de cisalhamento paralela ao acamamento onde aparece estreita $\wedge$ faixa milonítica efoliationfish. A SE da foto aparece uma ramificação de alto ângulo. Foto 3. Falha F2 entre setores II e III. À esquerda de F2, o acamamento mostra-se parcialmente obliterado pêlos planos de cisalhamento. Foto 4. Detalhe da foto 3, com milonito envolvendo pod de quartzito (p)

Plate 1 - Photo 1. Sector I of the outcrop, depicting bedding (A), bedding-parallel shear zones (P) corresponding to flats, and high angle shear zones, splaying from the sub-horizontal planes (R), corresponding to thrust ramps. Photo 2. Detail of Photo I, depicting bedding-parallel shear zones with narrow mylonitic band and foliation fish. SE of the photograph a high angle splay is shown. Photo 3. F2 Fault between sectors II and III. On the Left of F2 the bedding is partially obliterated by shear planes. Photo 4. Detail of photograph 3 with mylonite surrounding pod of quartzite (p)

a. Metamorfismo de carga e deslizamento interestratal são os mecanismos responsáveis pelo desenvolvimento da foliação paralela ao acamamento, particularmente nos níveis filíticos dentro de zonas indeformadas com plaquetas de sericita orientadas paralelamente ao acamamento, ressaltando a estrutura primária. $\mathrm{O}$ movimento entre os estratos desenvolveu-se provavelmente de maneira quase concomitante em diversos níveis entre pacotes de quartzito e entre as rochas do Supergrupo Espinhaço e seu embasamento, gerando descolamento basal (Fig. 4a).

b. Nucleação de dobras por deslizamento flexural (Fig. 4b). São dobras concêntricas, de dimensões decamétricas a decimétricas, com simetria monoclínica, eixo aproximadamente NNW-SSE e vergência para WSW. Apresentam clivagem em posição quase plano-axial, de orientação 147/60NE (Fig. 3b), com diferente morfologia, conforme os tipos litológicos envolvidos: clivagem ardosiana anastomosada nos quartzitos - e clivagem de crenulação - nos filitos.
Devido a sua menor competência, os filitos mostram dobras mais apertadas, com transposição pelo desenvolvimento progressivo da clivagem.

c. A evolução da deformação levou ao desenvolvimento de falhas de cavalgamento com morfologia lístrica, formando rampas e patamares (Fig. 4c). A morfologia dos cavalgamentos está condicionada às dobras macroscópicas com patamares paralelos ao acamamento, desenvolvidos principalmente nos flancos longos; os flancos curtos são truncados pelas rampas, subparalelamente à orientação da clivagem plano-axial. Os níveis filíticos tiveram importância preponderante no controle dos cavalgamentos, atuando como lubrificante, tanto durante o deslizamento interestratal inicial quanto durante o avanço das fatias de falha. No plano das falhas, a estrutura original dessa rocha foi destruída, transformando-se em filonito, entrecortado por veios de quartzo.

Nos planos de rampas e patamares, desenvolveram-se rochas miloníticas de espessura geralmente centimétrica, com 

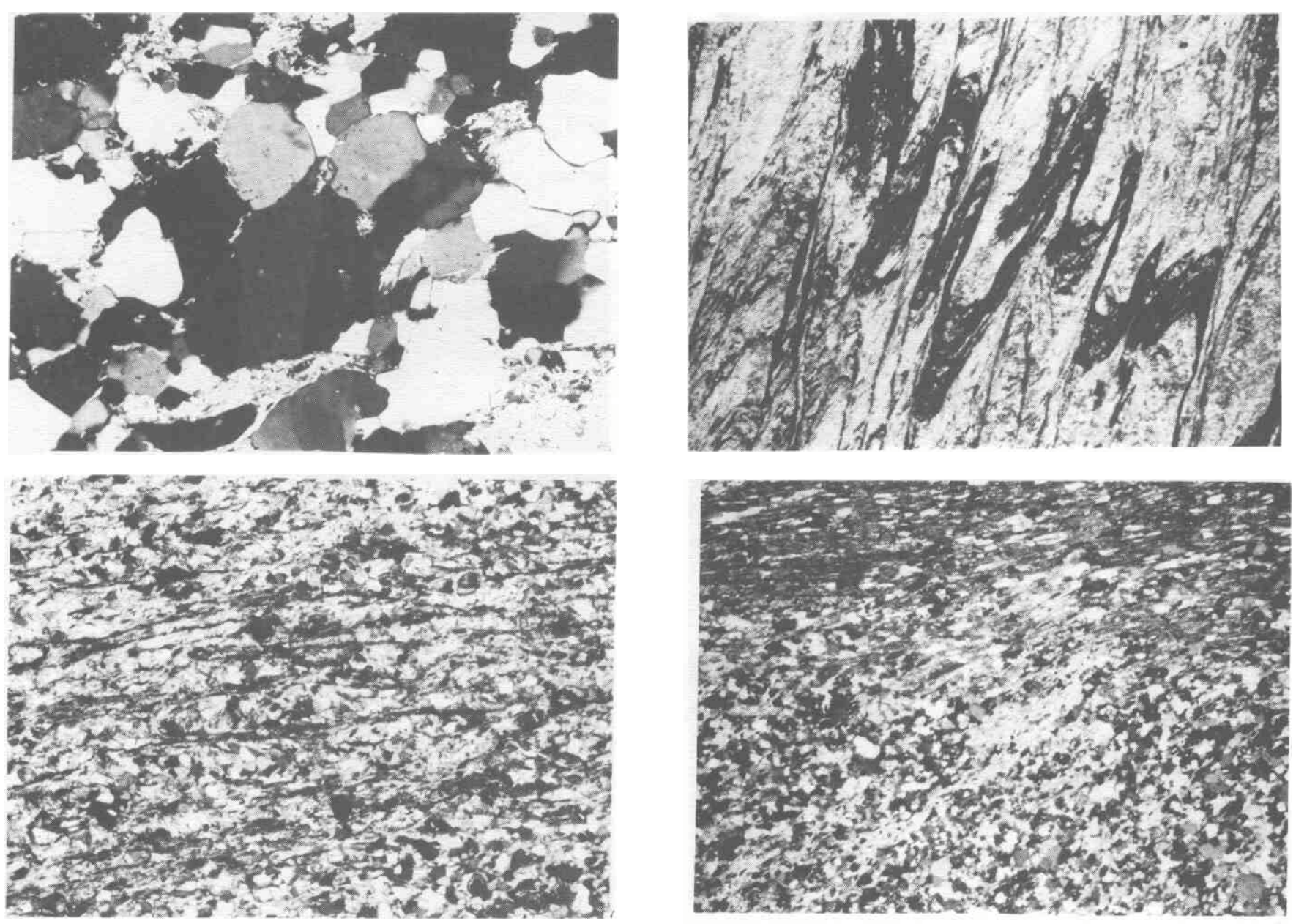

8

Prancha 2 - Foto 5. Fotomicrografia de quartzito com grãos mostrando extinção ondulante, bandas de deformação e recristalização parcial. Foto 6. F otomicro grafia de milonito da foto 4. Mostra palhetas de sericita definindo afoliação entre cristais neoformados de quartzo. Foto 7. Clivagem de crenulação no filito provocando a transposição do bandamento original caracterizado por níveis de hematita e sericita. Foto 8. Morfologia sigmoidal dafoliação no quartzito, próximo ao plano de cisalhamento, caracterizando estrutura do tipo $S / C$ sensu lato, que indica movimentação de ENE para WSW Plate 2 - Photo 5. Photomicrograph of deformed quartzite with grains displaying undulatory extinction, deformation bands and partial recrystallization. Photo 6. Photomicrography of mylonite from photograph 4. Oriented sericite flakes between new formed quartz grains define foliation. Photo 7. Crenulation cleavage on phyllite, resulting in the transposition of primary banding characterized by hematite and sericite. Photo 8. Shaped foliation in quartzite, due to the development of microscopic shear zone, characterizing a S/C-type structure sensu lato that indicates a ENE-WSW movement

diferentes graus de deformação, recristalização e segregação de material micáceo por dissolução por pressão do quartzo.

Nos patamares, a recorrência de cisalhamento paralelo ao acamamento resultou no aspecto sigmoidal adquirido pela foliação plano-axial que, rotacionada para o plano de movimentação, confunde-se com a foliação milonítica ali desenvolvida.

A tectônica evoluiu em regime eminentemente rúptil a dúctil-rúptil, em condições epiteliais, com dobras e cavalgamentos desenvolvidos dentro de um mesmo plano cinemático. Deduz-se este fato a partir da coalescência e paralelismo das estrias de deslizamento e da lineação mineral de estiramento, dos planos de clivagem plano-axial e das rampas de cavalgamento. $O$ fato de a clivagem associada aos dobramentos não estar precisamente em posição plano-axial indica, ainda, ligeira mudança no plano de deformação entre o estágio de nucleação das dobras e a formação da clivagem, mantendo-se então constante durante os cavalgamentos.
A mineralogia presente (sericita e quartzo) indica condições de metamorfismo de fácies xisto verde baixa, provavelmente com aumento progressivo da pressão litostática, pelo empilhamento das fatias tectônicas. $\mathrm{O}$ aquecimento do pacote, após o termino da deformação, permitiu a recuperação da estrutura cristalina do quartzo e sua recristalização estática, com o desenvolvimento de textura poligonal com formação de pontos triplos. Não se pode constatar, diretamente no afloramento, estruturação em duplex com a repetição da sequência em andares superpostos, embora as estruturas encontradas, aliadas à espessura anómala dos quartzitos na área, indiquem que este tipo de desenvolvimento tenha ocorrido na região.

Rolim (1992) e Rolim et al (1992) chegaram a conclusões semelhantes em trabalhos em diferentes escalas, levando a crer que os resultados ora apresentados tem validade regional para toda a porção ocidental da Serra do Espinhaço. 


\section{REFERENCIAS BIBLIOGRÁFICAS}

ALMEIDA ABREU, P.A. 1993. A Evolução Geodinâmica da Serra do Espinhaço Meridional, Minas Gerais, Brasil. Freiburg. 150 p. (Tese de Doutoramento, Univ. Albert-Ludwig)

ALMEIDA ABREU,P.A.; FERNANDES, P.C.O.; KNAUER, L.G.; HARTMANN, M.B; DONATO, M. T. R - SCHORSCHER, H.D. 1986. Elementos da zona de cisalhamento dúctil da borda oriental da Serra do Espinhaço, Minas Gerais. In: CONGR. BRÁS. GEOL., 34. Goiânia, 1986. Anais... Goiânia, SBG. v. 3, p. 1215-1231.

DOSSIN, LA; UHLEIN, A.; DOSSIN, T.M. 1984. Geologia da Faixa Móvel Espinhaco em sua porção meridional - MG. In: CONGR. BRÁS. GEOL., 33. Rio de Janeiro. Anais... Rio de Janeiro, SBG. v. 7 p. $3118-3122$

HERGESELL, G. 1984. Das Prãkambrium am Ostrand der Mrdlichen Serra do Cipó (Serra do Espinhaço, Minas Gerais, Brasilien). Freiburg. 247 p. (Tese de Doutoramento, Univ. Albert-Ludwig).

HERGESELL, G. 1985. Uma margem continental proterozóica na Serra do Cipó Setentrional (Serra do Espinhaço Meridional). In: SIMP. GEOL. MINAS GERAIS, 3. Belo Horizonte, 1985. Anais... Belo Horizonte, SBG. Boi. 5, p. 1-15.

PFLUG, R. 1968. A Geologia da Parte Meridional do Serra do Espinhaco e Zonas Adjacentes, Minas Gerais. Rio de Janeiro, DNPM/DGM. 51 p. (Boletim 26).

ROLIM, V. K. 1992. Uma interpretação das estruturas tectônicas do Supergrupo Espinhaco, baseado na geometria dos falhamentos de empurrão. In: SIMP. GEOL. MINAS GERAIS, 6. Ouro Preto, 1991. Anais... Ouro Preto, Rev. da Esc. de Minas, 45:75-77.
ROLIM, V. K; AGUIAR COSTA, S. M; SILVA, H. C. 1992. Um padrão de deformação para as formações superiores do Supergrupo Espinhaço Meridional. In: CONGR. BRÁS. GEOL., 37. São Paulo, 1992. Anais... 1992. São Paulo, SBG. v. 1, p. 295-297.

SCHÖLL, W. U. \& FOGACA, A. C. C. 1981. Projeto Mapeamento Geológico do Espinhaço Meridional, Quadrículas de Guinda e Gouveia. Diamantina, Centro de Geologia Eschwege. 44 p. (Relatório Interno)

UHLEIN, A. 1991. Transição Cráton - Faixa Dobrada: Exemplo do Cráton do São Francisco e da Faixa Aracuaí (Ciclo Brasiliano) no Estado de Minas Gerais. Aspectos estratigráficos e estruturais. São Paulo. 295 p. (Tese de Doutoramento, IG-USP).

UHLEIN, A.; TROMPETTE, R.; SILVA, M. E. 1986. Estruturação tectônica do Supergrupo Espinhaço na região de Diamantina (MG). Rev. Brás. Geoc., 16(2):212-216.

UHLEIN, A. \& TROMPETTE, R. 1993. Cisalhamento dúctil, dobras com eixo paralelo à lineação de estiramento e a estrutura da Faixa Araçuaí (MG). Geociências, 12(1):71-87.

MANUSCRITO A804

Recebido em 11 de novembro de 1993

Revisão do autor em 11 de marco de 1994 Revisão aceita em 28 de março de 1994 